\title{
Outcome of Corticosteroid Injection for Sciatica through the Caudal Route.
}

Nagendra Bahadur KC ${ }^{1}$, Shriraj Shrestha².

${ }^{1}$ Department of Anaesthesiology, Shree Birendra Hospital, Kathmandu; ${ }^{2}$ Department of Orthopedics, Kist Medical College Kathmandu Nepal.

\begin{abstract}
Introduction: Sciatica is an important medical problem with socioeconomic impact; its effective management remains a challenge. Approximately $80 \%$ of the total population experiences low back pain at some point in their lives which may be associated with sciatica. As it is more common in adult working group, the pain caused by sciatica can incapacitate a person fromdoing his or her normal work. So the goal of our treatment is not to cure anatomic abnormalities but rather to reduce pain, which allows the patient to engage in early rehabilitation and return to a more normal lifestyle.
\end{abstract}

Methods: Fifty patients were initially included in the study and all patients received three injection of $4 \mathrm{ml}$ methyle prednisolone acetate $(160 \mathrm{mg})$ and $6 \mathrm{ml}$ of Normal saline that is of total volume $10 \mathrm{ml}$.at an interval of 48 hours. Among 50 study patients, five patients dropped out in subsequent follow-up. So only forty-five patients were analyzed for final results.

Results: The mean age of the patient was 37.53 years, majority between $30-56$ years. Female who were involved in household activities dominated the study group. Comparing the mean (SD) VAS score on the day of presentation 70.00 (16.78) and on $35^{\text {th }}$ day 17.89 (25.23) so it was found to be statistically significant $(\mathrm{P}<0.001)$. None of the patients in the study had motor weakness and none of them developed serious complications. But $12(26.7 \%)$ patients developed transient headache after the procedure.

Conclusions: As the goal of our treatment was symptomatic pain relief, most of the patient's pain improved at 2 weeks after the steroid injection with no severe complication. This was short term study with encouraging results, but larger scale and longer period of follow ups required for better results.

Keywords: backache; caudal; epidural steroid;sciatica.

\section{INTRODUCTION}

Sciatica is the term applied to the condition of pain in the area of distribution of the sciatic nerve ${ }^{1}$.Sciatica is an important medical problem with socioeconomic impact; its effective management remains a challenge. Approximately $80 \%$ of the total population experiences low back pain at some point in their lives which may be associated with sciatica. As it is more common in adult working group, the pain caused by sciatica can incapacitate a person from doing his or her normal work. So the goal of our treatment is not to cure anatomic abnormalities but rather to reduce pain, which allows the patient to engage in early rehabilitation and return to a more normal lifestyle. Exerciseprogrammes combined with early return to normal activities havebeen shown to be beneficial in chronic low back pain with sciatica. Otherinterventions may also have a beneficial effect

Correspondance:

Dr. Nagendra Bahadur KC

Department of Anaesthesiology, Shree Birendra Hospital, Kathmandu.

Email:drnkcbinita@gmail.com 
like Bed rest with NSAIDS, Traction, Corsets, Yoga, Ultrasounds massage with Anti-inflammatory gel and even Operative methods like Laminectomy with Discectomy can also be done to treat the low back pain. One of the important alternatives isEpiduralinjection of steroids at the affected area for a chronic low back pain where other conservative methods failed to relieve pain. We aimed at testing the effectiveness of three epidural corticosteroid injections at 48 hour intervals for symptomatic management of sciatica as it is the recommended method in France. ${ }^{2}$

In 1901 the first reports were published of epidural injections of cocaine for low back pain and sciatica. In 1930 Evans reported good results in 22 of 40 patients treated with procaine and saline injection into the sacral epidural space for unilateral sciatica, and in the early 1950s Robecchi and Capral were the first to report epidural injection of cortisone into the first sacral neuroforamen for the treatment of low back pain ${ }^{3}$.

\section{METHODS}

This was a prospective interventional study done inShree Birendra Hospital and KIST Medical college Teaching Hospital in 18 months (Dec 2008 to June2010) with total of 50 patients were collected for study initially, but 5 patients were lost after first follow up. Hence, only 45 cases were included in the final data analysis.In our study, methyl-prednisolone which has predominantly anti-inflammatory action was used. We deposited methyl-prednisolone in the epidural space through the caudal route because it is easy to perform, cost effective and less complication. Our main aim in this study is to determine the efficacy of epidural corticosteroid injection through caudal route in sciatica. To record the pain status using visual analogue scale (VAS) after corticosteroid injection and to assess the SLRT ( traight Leg Raising Test). During Pre anesthetic Checkup, detail Performa was filled up with identification of the patients including address, telephone number (if possible). Patients were not admitted but explained and prepared to spend several hours to recover from the procedure.Proper history of pain with its duration, onset, location, radiation, and effect of position, aggravating and relieving factors and any risk factors were asked.Patients job description along with daily activities and work leisure activities hampered and their anxiety towards back pain with sciatica was noted.After the systemic examination, the hip and sacro-iliac joint was thoroughly examined as any pathology in these areas which is causing bach pain. The patient was examined in walking, standing and lying position. Special test like SLRT was done, as it is one of the tension sign indicative of sciatic nerve irritability.

The procedure was done in Operation Theater, attached with monitor. Patient is put in prone position, with a bolster under the pelvis. With all aseptic precaution, painting and draping was done from lumbosacral junction to the coccyx. The sacral hiatus, located between the two horns of sacral cornu was identified. The soft tissue and skin were anaesthetized with $1 \%$ xylocaine.

A 18' Gauge 2" straight beveled needle was advanced between the sacral cornu at about 45 degree, until contact with sacrum was made.The needle was redirected more cephalic, horizontal and parallel to the table, advancing into the sacral canal through the sacrococcygeal ligament and into the epidural space. Aspiration was done for blood or Cerebrospinal fluid and was checked for minimal resistance to air with a $2 \mathrm{ml}$ syringe and was palpated over the sacral region. $10 \mathrm{ml}$ volume containing $4 \mathrm{ml}$ of methyl prednisolone acetate (160mg) and $6 \mathrm{ml}$ of sterile normal saline was injected though this route. The patient received three injections at 48 hours interval.Bed rest, back exercise and lumber belts were authorized but advised to avoid NSAIDs and Narcotics.

\section{RESULTS}

Of the 50 patients recruited, five patients were lost in subsequent follow up and were excluded from the study. Hence only 45 cases were analyzed for the final result. The entirepatients were diagnosed as a case of sciatica. Total 45 patients were evaluated during the study out of which $27(60 \%)$ were female patients and $18(40 \%)$ were male patients. The minimum age in the study was 22 years and the maximum was 56 years. The mean age of the group was 37.53 years with SD of 8.99. The minimum weight in the study group was $40 \mathrm{~kg}$ and the maximum was $82 \mathrm{~kg}$. The mean weight of the group was $60.89 \mathrm{~kg}$ with a SD of $12.31 .48 .9 \%$ of the patient was of household activities, $35.6 \%$ were laborers and $15.6 \%$ were sedentary workers. Out of 45 patients $82.2 \%$ were married and $17.8 \%$ were unmarried. $53.3 \%$ of the patient had complaints in 
their right lower limb and $46.7 \%$ of the patient had complaints in their left lower limb. $71.1 \%$ of the patient had $\mathrm{L}_{5}$ nerve root involvement and $28.9 \%$ of the patient had $S_{1}$ nerve root involvement. The minimum duration of pain was 15 days and the maximum duration of pain was 180 days with a mean of 96.78days with a SD of 46.67.Post procedure Transient Headache was present in $12(26.7 \%)$ patients and were treated with simple analgesic like Paracetamol and advised to drink large volume of fluids.

As the mean VAS pain score has been progressively decreasing during consecutive follow ups. Comparing the mean (SD) VAS on the day of presentation 70.00 (16.78) and on $35^{\text {th }}$ day 17.89 (25.23) was found to be statistically significant $(\mathrm{P}<0.001)$ (Table1).

Table 1.The mean VAS pain score on the day of presentation and $35^{\text {th }}$ day.

\begin{tabular}{|l|r|r|r|r|r|}
\hline & N & Minimum & Maximum & Mean & $\begin{array}{c}\text { Std. De- } \\
\text { viation }\end{array}$ \\
\hline $\begin{array}{l}\text { VAS on } \\
\text { presentation }\end{array}$ & 45 & 50 & 100 & 70.00 & 16.787 \\
\hline $\begin{array}{l}\text { VAS on } \\
\text { 35th day }\end{array}$ & 45 & 0 & 90 & 17.89 & 25.237 \\
\hline
\end{tabular}

$\mathrm{P}<0.001$

Table 3. Radiation to right lower limb.

\begin{tabular}{|l|r|r|r|r|r|}
\hline & \multicolumn{1}{|c|}{ N } & \multicolumn{1}{|c|}{ Minimum } & \multicolumn{1}{c|}{ Maximum } & \multicolumn{1}{c|}{ Mean } & \multicolumn{1}{c|}{ Std. Deviation } \\
\hline SLRT on presentation & 24 & 10 & 70 & 40.42 & 13.667 \\
\hline SLRT on $5^{\text {th }}$ day & 24 & 20 & 80 & 50.63 & 15.695 \\
\hline SLRT on $20^{\text {th }}$ day & 24 & 40 & 90 & 72.71 & 15.179 \\
\hline SLRT on $35^{\text {th }}$ day & 24 & 20 & 90 & 77.08 & 19.388 \\
\hline
\end{tabular}

The mean (SD) SLRT of right lower limb on the day of presentation was 40.42 (13.66) which improved to a mean ( SD) of 77.08 (19.38) on $35^{\text {th }}$ day, which was statistically significant $(\mathrm{p}<0.001)$ (Table 3$)$

Table 4. Radiation to right lower limb

\begin{tabular}{|l|l|l|}
\hline & Mean & Std Deviation \\
\hline At presentation & 40.42 & 13.667 \\
\hline On $3^{\text {th }}$ day & 77.08 & 19.388 \\
\hline
\end{tabular}

$\mathrm{P}<0.001$

The mean SLRT of left lower limb was 36.43 on the day of presentation and 42.14, 65.95 and 72.86 on $5^{\text {th }}$, $20^{\text {th }}$ and $35^{\text {th }}$ post injection days respectively (Table 5 ).
Table 2. Corelation between VAS mean pain score on presentation and $35^{\text {th }}$ day with the involvement of different nerve root (Table 2).

\begin{tabular}{|l|l|l|}
\hline & $\begin{array}{l}\text { VAS mean (SD) } \\
\text { pain on the day of } \\
\text { presentation }\end{array}$ & $\begin{array}{l}\text { VAS mean ( SD) } \\
\text { pain on } 35^{\text {th }} \text { day }\end{array}$ \\
\hline L5 nerve root & $68.44(16.28)$ & $18.28(23.37)$ \\
\hline S1 nerve root & $73.85(18.04)$ & $16.92(30.38)$ \\
\hline
\end{tabular}

Effect on two different nerve roots (L5 and S1 nerve root ) shows no statistical significance $(\mathrm{p}=0.74)$.

The mean SLRT of right lower limb was 40.42 on the day of presentation and was 50.63, 72.71 and 77.08 on $5^{\text {th }}, 20^{\text {th }}$ and $35^{\text {th }}$ post injection days respectively (Table 3).
Table 5. Radiation to left lower limb

\begin{tabular}{|l|r|r|r|r|r|}
\hline & N & \multicolumn{1}{|c|}{$\begin{array}{c}\text { Mini- } \\
\text { mum }\end{array}$} & $\begin{array}{c}\text { Maxi- } \\
\text { mum }\end{array}$ & Mean & $\begin{array}{c}\text { Std. } \\
\text { Devia- } \\
\text { tion }\end{array}$ \\
\hline $\begin{array}{l}\text { SLRT on } \\
\text { presentation }\end{array}$ & 21 & 20 & 60 & 36.43 & 11.417 \\
\hline $\begin{array}{l}\text { SLRT on 5 } \\
\text { day }\end{array}$ & 21 & 20 & 60 & 42.14 & 10.905 \\
\hline $\begin{array}{l}\text { SLRT on } \\
2^{\text {th }} \text { day }\end{array}$ & 21 & 30 & 90 & 65.95 & 18.140 \\
\hline $\begin{array}{l}\text { SLRT on } \\
3^{\text {th }} \text { day }\end{array}$ & 21 & 30 & 90 & 72.86 & 19.402 \\
\hline
\end{tabular}

The mean (SD) SLRT of left lower limb on the day of presentation was 36.43 (11.417) which improved to a mean ( SD) of $72.86(19.402)$ on $35^{\text {th }}$ day, which was statistically significant $(\mathrm{p}<0.001)$ (Table 6) 
Table 6. Radiation to left lower limb

\begin{tabular}{|l|l|l|}
\hline & Mean & Std Deviation \\
\hline At presentation & 36.43 & 11.417 \\
\hline On $35^{\text {th }}$ day & 72.86 & 19.402 \\
\hline
\end{tabular}

$\mathbf{P}<\mathbf{0 . 0 0 1}$

\section{DISCUSSION}

Sciatica accounts a large group of patients attending orthopedicoutpatient department and is a major health problem incapacitating daily activities of life. Study result given by Hult states that upto $80 \%$ of people are affected by back pain at sometimes in their life which may be associated with sciatica ${ }^{3}$. Considering the natural history of back pain it has a spontaneous improvement over time. So the goal of epidural injection is not to cure anatomic abnormalities but rather to reduce pain, which allows patient to engage in rehabilitation and to return to a more normal life style ${ }^{4}$,otherwise these group of patients continues to be a financial, social and economic burden to the society.

There are both surgical and non-surgical methods for treating sciatica, but our study includes a minimal invasive method of giving epidural steroid injections through the caudal route which acts by its antiinflammatory action around the nerve root and relive pain. In one of the study once a patient is diagnosed with lumbar radiculopathy and herniated nucleus pulposus or lumbar spinal stenosis, the patient is likely to receive a course of non-operative treatment. In most cases, these patients had improvement in their symptoms over time and do not need an operative intervention. These treatments include short bed rest, medications, physio therapy, and epidural steroid injections $s^{5}$. In our study we have used three injections of $4 \mathrm{ml}$ of methyl prednisolone $(160 \mathrm{mg})$ with $6 \mathrm{ml}$ of isotonic saline at an interval of 48 hours through caudal route, as it is the recommended method in France for the management of sciatica ${ }^{2}$.Epidural steroid injections have long been used by multiple disciplines in the treatment of low back pain. Different regime for epidural injection has been used but none have been proved best. A study done by A . Anwar. I. Zaidah and Rozita ${ }^{6}$ compared the effectiveness of triamcinaloneacetonide and methyl prednisolone acetate in patient with sciatica and concluded that there were marked improvement in symptoms in both agents but there were no difference in term of superiority from one agent to another. Epidural injection of methyl prednisolone can be given through different routes, a study done on 200 consecutive patients referred to a pain clinic for an epidural injection of steroid, one group had lumbar approachand another group had caudal approach to the epidural space. Both groupsthen had epidurography performed using Omnipaque and an imageintensifier to determine the position of theneedle. They found that $93 \%$ of lumbarand $64 \%$ of caudal epidural injections were correctly placed ${ }^{7}$. Hence in our study the epidural space might probably be equally missed as the method doesn't include a fluoroscopic guidance and contrast injection, which increases the cost and side effect to the patient.

As far as gender distribution is concerned, we found that females are more predominant, with a female to male ratio of 1.5:1. As female population in our community are exposed to both household activities and field works but they still regard themselves as doing household activities only. Whereas male population are subjected only to field works. This may be the reason why females are more prone to develop back pain with sciatica in our community. The VAS mean pain score was statically significant $(p<0.001)$ in both the groups from the day of presentation to $35^{\text {th }}$ day.But a study conducted in 600 autopsy specimens showed disc degeneration to be more common among the male population, without knowing the reason ${ }^{8}$.

Our study showed involvement of fifth lumbar root $(71.1 \%)$ more than first sacral root $(28.9 \%)$. This shows that the degeneration of L4-5 vertebrae more than $\mathrm{L}_{5}-\mathrm{S}_{1}$ vertebrae which is similar to a study done by Miller et al ${ }^{8}$ and Clarke NMP et al ${ }^{9}$. Dividing the patient in our study into two groups i.e. one with L5 nerve root involvement and other with $\mathrm{S} 1$ nerve root involvement, there was improvement in VAS mean pain score in both the groups regarding the time from the day of presentation to $35^{\text {th }}$ day and was statistically significant $(p<0.001)$. In our study low back pain with radiation was evaluated on the basis of VAS score and SLRT, on the day of presentation, $5^{\text {th }}, 20^{\text {th }}$ and $35^{\text {th }}$ post injection day.

VAS mean pain score was 70 with SD of 16.78 on the day of presentation which has decreased to 57.56 with $\mathrm{SD}$ of 17.07 on $5^{\text {th }}$ post injection day and the difference was found to be statistically significant $(\mathrm{p}<0.001)$ further on $20^{\text {th }}$ post injection day the VAS mean pain score was 28.56 with SD of 16.60, which as compared to $5^{\text {th }}$ day was decreased and was statistically significant $(p<0.001)$. Similarly the VAS mean pain 
score on $35^{\text {th }}$ post injection day was 17.89 with SD of 25.23 , which as compared to $20^{\text {th }}$ day, was also found to be statistically significant $(p<0.001)$. There was a significant improvement in VAS mean pain score from the day of presentation to $35^{\text {th }}$ day and was statistically significant $(\mathrm{p}<0.001)$.

In a double blind, randomized study of epidural steroid treatment of disc herniation and spinal stenosis found no difference in the result at 6 months between placebo and a single epidural injection ${ }^{10}$. We also agreed that the epidural steroid injections are not a cure for disc disease, but they do offer relatively prolong pain free interval without intake of analgesic (NSAID, narcotics) . Most studies show a $60 \%$ to $85 \%$ short term success rate that falls to a $30 \%$ to $40 \%$ long term (6 months) good result rate. The local effect of steroids has been shown to last at least 3 weeks at a therapeutic level ${ }^{3}$.

Both the surgeon and patients must realize that the management of sciatica by epidural corticosteroid injection is not a cure but may provide symptomatic relief. It neither stops the pathological processes that allowed the herniation to occur nor restores it back to normal state. The patient must still practice good posture and body mechanics after the procedure. If prolonged relief is to be expected, then some permanent modification of the patient's lifestyle may be necessary ${ }^{3}$.Thereforeepidural corticosteroid injection through caudal route is effective for short duration but its long term efficacy is yet to be studied.

\section{CONCLUSIONS}

Giving corticosteroid injection through caudal route is easy and safe way of treating sciatica when conservative treatment fails. This procedure of giving injection was well tolerated by most of the patients and none of the patient developed serious complication. This study showed that the patients are benefited from epidural steroid injection through caudal route.

\section{REFERENCES}

1. Turek SL, Sciatic nerve and Sciatica, Orthopaedics principles and their applications, 4th edition, Vol 1,509-13.

2. Valat JP, Giraudeau B, Rozenberg S, Goupille P, Bourgeois P,VMicheau-Beaugendre V, Soubrier M, Richard S, Thomas E. Epidural corticosteroid injections for sciatica: a randomized, double blind, control clinical trial. Annals of the Rheumatic Diseases. 2003;1(5):317-21

3. Canale ST, Lower Back Pain and Disorders of Intervertebral Discs, Campbell's operative orthopaedics, 10th edition, Vol 2,1955-2017

4. Stanczak J, Blankenbaker DG. Efficacy of epidural injection of kenalog and celestone in the treatment of low back pain. American Journal of Roentgenology. 2003;181:1255-8. http://dx.doi.org/10.2214/ajr.181.5.1811255

5. Saechin K. Non operative treatment for lumbar disc herniation with radiculopathy and for lumbar spinal stenosis.Current opinion in orthopedics. 1999;10(2):13741. http://dx.doi.org/10.1097/00001433-199904000-00009

6. Zaidah AAI. Prospective randomized single blind study of epidural steroid injection comparing triamcinolone acetonide with methylprednisolone acetate. APLAR journal of Rheumatology.2005;(1):51- 53.

7. Price CM, Rogers PD. Comparisons of the caudal and lumbar approaches to the epidural space. Ann Rheum Dis. 2000;59:879-82. http://dx.doi.org/10.1136/ard.59.11.879

8. Miller JAA, Schmatz C, Schultz AB. Lumbar disc degeneration : correlation with age, sex and spine level in 600 autopsy specimens. Spine. $1988 ; 13: 2173$.http://dx.doi. org/10.1097/00007632-198802000-00008

9. Clarke NMP, Cleak DK. Intervertebral lumbar disc prolpase in children and adolescents. J pediatrorthop. 1983;3:202. http://dx.doi.org/10.1097/01241398-198305000-00009

10. Cuckler JM, Bernini PA, Wiesel SW, et al: The use of epidural steroids in the treatment of lumbar radicular pain. JBJS. 1985;67(63):51-2. 